\title{
A Neuronal Ensemble in the Rostral Agranular Insula Tracks Cocaine-Induced Devaluation of Natural Reward and Predicts Cocaine Seeking
}

\author{
Travis M. Moschak, ๑Xuefei Wang, and Regina M. Carelli \\ Department of Psychology and Neuroscience, University of North Carolina, Chapel Hill, Chapel Hill, North Carolina 27599
}

In substance use disorders, negative affect associated with drug withdrawal can elicit strong drug craving and promote relapse. One brain region implicated in those processes is the rostral agranular insular cortex (RAIC), although precisely how this region encodes negative affect associated with drug seeking is unknown. Here, a preclinical model was used where RAIC activity was examined in male Sprague Dawley rats during intraoral infusions of a sweet (saccharin) paired with impending but delayed access to cocaine self-administration, and for comparative purposes, during the sweet predicting saline self-administration or injection of lithium chloride (LiCl), or during intraoral infusions of a bitter taste (quinine). Consistent with previous work, cocaine-paired saccharin, LiCl-paired saccharin, and quinine all elicited aversive taste reactivity. However, the aversive taste reactivity elicited by the cocaine-paired tastant was qualitatively different from that evoked by the other two agents. Furthermore, differences in taste reactivity were reflected in RAIC cell firing, where distinct shifts in neural signaling were observed specifically after cocaine but not LiCl conditioning. Notably, low motivation for cocaine (indicated by low loading and slower latencies to lever press) was correlated with this shift in RAIC signaling, but aversive (gaping) responses were not. Collectively, these findings indicate that cocaine-paired tastants elicit unique aspects of aversive behaviors that differ from traditional conditioned taste aversion $(\mathrm{LiCl})$ or quinine and that the RAIC plays a role in modulating drug-seeking behaviors driven by drug-induced dysphoria (craving), but not negative affect per se.

Key words: addiction; behavior; electrophysiology; insula; rat; reward

Significance Statement

In substance use disorders, negative affect associated with drug cues can elicit craving and promote relapse; however, the underlying neurocircuitry of this phenomenon is unknown. Here, we investigated the role of the rostral agranular insula cortex (RAIC) in these processes using a preclinical model wherein intraoral delivery of a sweet is paired with delayed access to cocaine selfadministration. The taste comes to elicit negative affect that predicts heightened drug seeking. Here, we found that a population of RAIC neurons became inhibited during presentation of the cocaine-paired tastant (when negative affect is high) and that this inhibitory neural profile predicted lower drug seeking. These findings suggest that the RAIC may function to oppose cue-induced cocaine craving and help reduce motivation for the drug.

\section{Introduction}

In substance use disorders, negative reinforcement can be a powerful motivator for repeated drug use. Individuals suffering

Received May 11, 2018; revised July 31, 2018; accepted Aug. 14, 2018.

Author contributions: T.M.M. and R.M.C. designed research; T.M.M. and X.W. performed research; T.M.M. and X.W. analyzed data.

This work was supported by National Institute on Drug Abuse (NIDA) Grant DA014339 to R.M.C. Cocaine used in these experiments was generously provided by the NIDA Drug Supply Program. We thank Rachel Haake, Dr. Elizabeth West, and Dr. Seth Hurley for technical assistance.

The authors declare no competing financial interests.

Correspondence should be addressed to Dr. Regina M. Carelli, CB\#3270 Davie Hall, Department of Psychology and Neuroscience, University of North Carolina, Chapel Hill, Chapel Hill, NC 27599. E-mail: rcarelli@unc.edu.

DOI:10.1523/JNEUROSCI.1195-18.2018

Copyright $\odot 2018$ the authors $\quad 0270-6474 / 18 / 388463-10 \$ 15.00 / 0$ negative affect associated with drug withdrawal (e.g., dysphoria, anxiety, irritability) resume drug taking after abstinence to ameliorate this dysphoric state (Koob and Volkow, 2010; Wise and Koob, 2014). Importantly, negative affect is thought to drive craving for abused substances (Solomon and Corbit, 1974; Koob and Volkow, 2010), and heightened negative affect or withdrawal increases selfreported craving (Brandon, 1994; Sinha et al., 2006). As such, it is critical to investigate the underlying neurocircuitry of negative affect and drug craving to fully understand their role in addiction.

The insula plays an important role in these processes. Human neuroimaging studies revealed that insular activity increases when subjects are shown cues associated with abused substances (Wang et al., 1999; Kilts et al., 2001). Conversely, subjects asked 
to suppress their craving for drugs or food exhibit decreased BOLD activity in the insula (Wang et al., 2009; Volkow et al., 2010). Likewise, cigarette-smoking patients with insula lesions have reduced craving for cigarettes (Naqvi et al., 2007; Gaznick et al., 2014). Furthermore, negative affect during withdrawal is correlated with insular activity; manipulating the withdrawal state alters insula activity after drug cues (Gloria et al., 2009). However, few preclinical studies have investigated the role of the insula in these phenomena, in large part because of a lack of behavioral models to directly assess those states in rodents.

Our laboratory uses a preclinical model in which a cocaineassociated taste cue that predicts impending but delayed cocaine availability elicits a negative affective state associated with heightened drug seeking (Wheeler et al., 2008, 2011; Carelli and West, 2014; Colechio et al., 2014; Green et al., 2015). Here, rats receive multiple discrete intraoral saccharin infusions over $\sim 30-45$ min, followed by $2 \mathrm{~h}$ of cocaine self-administration. Orofacial responses to the sweet, which are examined via taste reactivity (Grill and Norgren, 1978), reflect its palatability and the affective state it elicits (Berridge, 2000). After repeated taste-drug pairings, the saccharin becomes unpalatable as it is associated with impending, but delayed, opportunity to self-administer cocaine (Wheeler et al., 2008, 2011; Wheeler and Carelli, 2009; Carelli and West, 2014; Green et al., 2015). We hypothesize that the cocainepaired tastant serves as a predictor of impending cocaine and that anticipation of drug availability precipitates a conditioned aversive state. Thus, a critical feature of this task is that rats must "wait" for the drug and this waiting period is aversive. In support, aversive taste reactivity is not observed when cocaine immediately follows tastant infusion (Parker, 1995). Furthermore, rats that exhibit the most aversive responses to cocaine-paired saccharin are the most motivated to subsequently consume cocaine, suggesting that the aversion may reflect drug craving (Wheeler et al., 2008; Colechio et al., 2014; Green et al., 2015). We have also shown that the nucleus accumbens (NAc) plays a key role in this process. Specifically, NAc neurons and rapid dopamine release in the NAc track the emergence of drug-induced negative affect (Wheeler et al., 2008, 2011; Haake et al., 2018), and the latter is causally linked to it (Hurley et al., 2017).

An anterior subregion of the insula, the rostral agranular insula cortex (RAIC), sends a direct projection to the NAc (Jasmin et al., 2004) and may, therefore, play a role in drug-induced negative affect. The RAIC is implicated in conditioned place preference (Contreras et al., 2012), drug seeking (Seif et al., 2013; Cosme et al., 2015; Arguello et al., 2017; Venniro et al., 2017), and cocaine-induced devaluation of natural reward (Geddes et al., 2008). Here, we investigated whether insula neurons track negative affect elicited by a tastant paired with delayed cocaine, and its relationship with drug seeking/taking. Furthermore, to determine the specificity of responses to the cocaine-paired tastant, we also examined insula firing during infusion of saccharin paired with $\mathrm{LiCl}$ injection (i.e., traditional conditioned taste aversion) and during intraoral infusion of the innately bitter tastant quinine.

\section{Materials and Methods}

Subjects and surgery

Thirty-eight male Sprague Dawley rats (60-90 d, 300-325 g; Envigo/ Harlan) were singly housed with a $12 \mathrm{~h}$ light/dark cycle. Experiments were conducted during the dark phase. Standard laboratory chow (Prolab Isopro RMH3000, Purina) was available ad libitum. Rats were mildly water restricted $(20-25 \mathrm{ml} / \mathrm{d})$ to no less than $85 \%$ of free feed body weight, except during postoperative recovery when water was freely available.
Rats were anesthetized with a ketamine (100 mg/kg)/xylazine (10 mg/ $\mathrm{kg}$ ) mixture and received an intraoral cannula, an intrajugular catheter, and bilateral electrophysiology arrays in a single surgery, using established methods routinely used in our laboratory (Wheeler et al., 2008). The intraoral cannula consisted of a length of PE100 tubing inserted lateral to the upper molars and exteriorized at the top of the head, fixed in place by Teflon washers at both ends. A custom sterile polyurethane catheter (Access Technologies) was inserted into the right jugular vein and routed subcutaneously to an external attachment point on the back. Eight-wire electrophysiology arrays (NB Labs) were implanted bilaterally in the RAIC (AP, $+2.7 \mathrm{~mm}$; ML, $\pm 4.2 \mathrm{~mm}$ relative to bregma; $\mathrm{DV},-5.8$ $\mathrm{mm}$ from skull surface). For each array, a ground wire was wrapped around a screw and implanted into the brain. Arrays and screws were fixed into place with dental acrylic (Lang Dental). Animals were given 1 week of recovery with ad libitum food and water. All procedures were approved by the University of North Carolina at Chapel Hill Institutional Animal Care and Use Committee.

\section{Apparatus}

All experiments were conducted in $43 \times 43 \times 53 \mathrm{~cm}$ operant chambers (MED Associates) housed in copper mesh Faraday cage soundattenuating cubicles. Each operant chamber was equipped with a food/ water delivery port flanked by two retractable levers. Above each lever was a cue light, and the opposite wall contained a houselight and a tone generator. An electronically driven pump was used to deliver intraoral and intrajugular solutions via Tygon tubing. All tasks and behavioral events were controlled and recorded by a computer using MED-PC software (MED Associates). A tilted mirror positioned underneath each chamber allowed visualization and recording of taste reactivity during intraoral infusions.

\section{Electrophysiology}

Electrophysiological recordings were conducted as described previously (Carelli et al., 2000; Hollander and Carelli, 2005; Wheeler et al., 2008; West and Carelli, 2016). Briefly, each rat was connected via $1 \times$ gain headstages and a flexible recording cable to a multichannel acquisition processor (MAP) system (Plexon) before the start of the experiment. A commutator (Crist Instrument) allowed for free movement within the chamber. Neuronal firing was recorded differentially between active and inactive (reference) wires; one reference wire was chosen within each array based on a lack of neuronal spike activity. On-line discrimination of neurons was conducted using waveform analysis provided in SortClient software (Plexon). A separate computer (MED Associates) was used to control the behavioral program and send transistor-transistor logic (TTL) pulses to time-stamp events within the MAP recording. Cell sorting was finalized afterward using the Offline Sorter software (Plexon) to perform additional principal component analyses. Auto-correlograms, interspike intervals, and waveform principal components were examined to ensure that putative cells had the biologically appropriate characteristics.

\section{Experimental design and statistical analysis}

Rats were initially trained in an operant chamber to press a lever for water and then underwent surgery as described above. After recovery, rats underwent a habituation session with intraoral water infusions. Subsequently, animals were assigned to one of the saline, cocaine, $\mathrm{LiCl}$, or quinine experiments listed below. Some animals were used in more than one experiment, as described below.

Saline conditioning. For each session, animals $(n=11)$ were given 45 intraoral infusions (VT-45 s schedule of delivery over $\sim 30-40 \mathrm{~min}$ ) of $0.15 \%$ saccharin $(133 \mu \mathrm{l}, 4 \mathrm{~s} /$ infusion; Fig. $1 A)$. Immediately after, animals were disconnected from the intraoral tubing and connected to a separate length of tubing used to deliver heparinized $0.9 \%$ saline through the rats' intrajugular catheter. Animals began a $2 \mathrm{~h}$ session in which they could press a cued lever on a FR1 schedule for saline (200 $\mu \mathrm{l} /$ infusion) coupled with delivery of a $20 \mathrm{~s}$ tone-light stimulus (during this $20 \mathrm{~s}$ period, further presses did not result in saline delivery). Animals underwent $14 \mathrm{~d}$ of conditioning, and taste reactivity and neural activity were recorded on days 1,7 , and 14 .

Cocaine conditioning. This group $(n=13)$ had an identical task as the saline group, but lever presses during the self-administration phase re- 
A

$$
\begin{gathered}
\text { Saline } \\
\text { Conditioning }
\end{gathered}
$$

B

\author{
Cocaine \\ Conditioning
}

C $\mathrm{LiCl}$
Conditioning

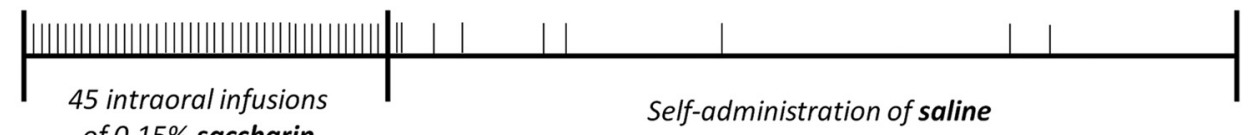
of $0.15 \%$ saccharin
45 intraoral infusions of $0.15 \%$ saccharin
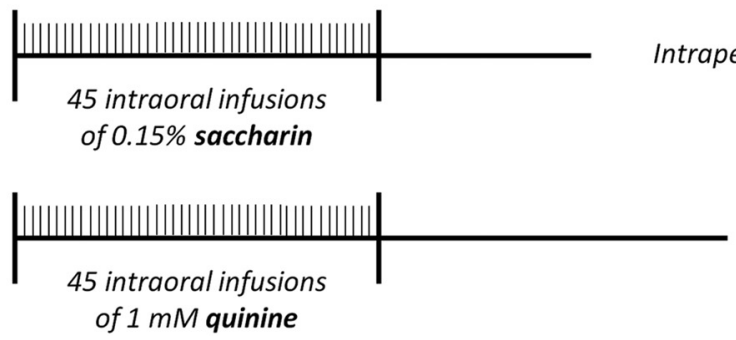

\section{of $1 \mathrm{mM}$ quinine}

No injection

\section{Quinine}

Figure 1. Task schematic for the different groups. A, Saline conditioning. Animals received 45 intraoral infusions of $0.15 \%$ saccharin $(0.13 \mathrm{ml} /$ infusion, over $\sim 34 \mathrm{~min})$. Immediately after, animals were disconnected from the intraoral line and connected to the intrajugular line. For the next $2 \mathrm{~h}$, the rats could press a lever to self-administer a $0.2 \mathrm{ml}$ bolus of $0.9 \%$ saline. $\boldsymbol{B}$, Cocaine conditioning. This group was identical to the saline group, except that animals self-administered cocaine $(0.33 \mathrm{mg} /$ infusion $)$ instead of saline. $C$, LiCl conditioning. In this group, animals underwent the same intraoral infusion procedure, but this was followed by an intraperitoneal injection of $127 \mathrm{mg} / \mathrm{kg} \mathrm{LiCl}$. D, Quinine. Instead of saccharin, animals received 45 intraoral infusions of $1 \mathrm{~mm}$ quinine. No injections or conditioning followed quinine infusions.

sulted in intravenous cocaine delivery $(0.33 \mathrm{mg} / 200 \mu \mathrm{l} /$ infusion; dissolved in heparinized $0.9 \%$ saline) instead of saline alone (Fig. $1 B$ ). Animals underwent $14 \mathrm{~d}$ of conditioning, and taste reactivity and neural activity were recorded on days 1,7 , and 14 .

$\mathrm{LiCl}$ conditioning. In this group $(n=14$, of which $n=9$ were previously in the naive quinine group and $n=5$ were naive), the intraoral infusion phase of the experiment remained the same as the other conditioning experiments, but animals subsequently received an intraperitoneal injection of $127 \mathrm{mg} / \mathrm{kg} \mathrm{LiCl}$ (instead of self-administration; Fig. 1C). Animals underwent $2 \mathrm{~d}$ of LiCl pairings, followed by a test day (saccharin infusion, but no $\mathrm{LiCl}$ ). Taste reactivity and neural activity were recorded on the first day of conditioning (day 1) and the test day 3 .

Quinine. Here, animals ( $n=23$, of which $n=7$ were previously in the cocaine group, $n=7$ were previously in the saline group, and $n=9$ were naive) had one intraoral session as above, but quinine (1 mM) was delivered instead of saccharin (quinine was not paired with anything; Fig. 1D). Taste reactivity and neural activity were recorded during the session.

For all animals that were run in more than one experimental condition, each had at least one session of 45 water infusions between experiments. For all behavioral and electrophysiological analyses, animals with a previous history in another experiment did not differ from experimentally naive animals, and their data were therefore analyzed together (see below).

\section{Behavioral analysis}

A video camera was used to record the orofacial activity of each rat from an angled mirror positioned below the operant chamber. Taste reactivity was assessed using a procedure developed by Grill and Norgren (1978) and used previously in our laboratory (Wheeler et al., 2008, 2011; Green et al., 2015; Hurley et al., 2017). Mouth movements in the $6 \mathrm{~s}$ after the start of intraoral infusion were recorded as aversive "gapes" if they matched a "triangle" shape, and tongue protrusions that crossed the midline were recorded as appetitive "licks." Instances of liquid dripping out of the mouth after infusions were recorded as "drips." Rapid forelimb flails, headshakes, and instances where the chin was rubbed against the floor were also recorded as measures of aversive taste reactivity. To assess the change in taste reactivity across the session, we divided the 45-trial session into five 9-trial bins. For all analyses comparing cocaine, $\mathrm{LiCl}$, and quinine, days 7 and 14 cocaine data and day $3 \mathrm{LiCl}$ data were used. During self-administration, we assessed the number of reinforcers obtained, cocaine $(\mathrm{mg} / \mathrm{kg})$ obtained, latency to first press, and number of "loading" responses. Loading behavior was defined as the number of rapid consecutive lever press responses early in the session that were less than half of the inter-reinforcer interval for the entire session; this measure has been previously correlated with measures of motivation to acquire drug (Carelli and Deadwyler, 1996; Wheeler et al., 2008). Latency values were not normally distributed and thus were transformed via a natural logarithm.

To analyze the shift in taste reactivity after conditioning, a one-way repeated-measures ANOVA was completed on both licks and gapes for days 1,7 , and 14 of saline or cocaine conditioning. For $\mathrm{LiCl}$ rats, a paired $t$ test was run on both licks and gapes for days 1 and 3 of conditioning. To compare the differences in aversive taste reactivity between the cocaine, $\mathrm{LiCl}$, and quinine groups, a one-way ANOVA was completed for both gapes and drips. To further analyze differences in the time course of aversive taste reactivity, a mixed $2 \times 5$ ANOVA with Group and Time Bin as the factors was used. Bonferroni corrections were used for relevant post hoc tests in all analyses. For repeated-measures analyses that did not pass Mauchly's test for sphericity, Huynh-Feldt-adjusted degrees of freedom were used.

\section{Electrophysiology}

Neurons were defined as "phasic" if they exhibited either a significant increase or decrease in firing rate to tastant infusion as described previously (Wheeler et al., 2008). Briefly, for intraoral infusions, a $5 \mathrm{~s}$ window was used that comprised five $1 \mathrm{~s}$ bins: a baseline $1 \mathrm{~s}$ bin before tastant infusion and four $1 \mathrm{~s}$ bins after infusion. A repeated-measures ANOVA was run on the five bins, with planned contrasts between each of the four bins and the baseline period. Neurons with significant increases or decreases in cell firing within the first two bins were considered "earlyfiring" neurons; those with significant increases or decreases in cell firing within the latter two bins were considered "late-firing" neurons.

To investigate the differences in neurons that modulated their activity after intraoral infusions, $\chi^{2}$ tests compared the proportion of nonphasic, inhibitory, and excitatory neurons (both early and late firing) across each day of conditioning for the saline, cocaine, and $\mathrm{LiCl}$ groups. The same analysis was completed for the quinine group but compared with unpaired saccharin. Finally, the aforementioned analyses were repeated looking separately at neurons in the rostral RAIC (AP, +3.0 or higher) and caudal RAIC (AP, +2.7 and lower) using Fisher's exact probability tests. To examine relationships to behavioral measures across test days 7 and 14, Pearson correlations were used to compare the percent of earlyfiring cells that were inhibitory to the number of gapes, loading presses, and latency to first press. From the correlations, we determined the co- 

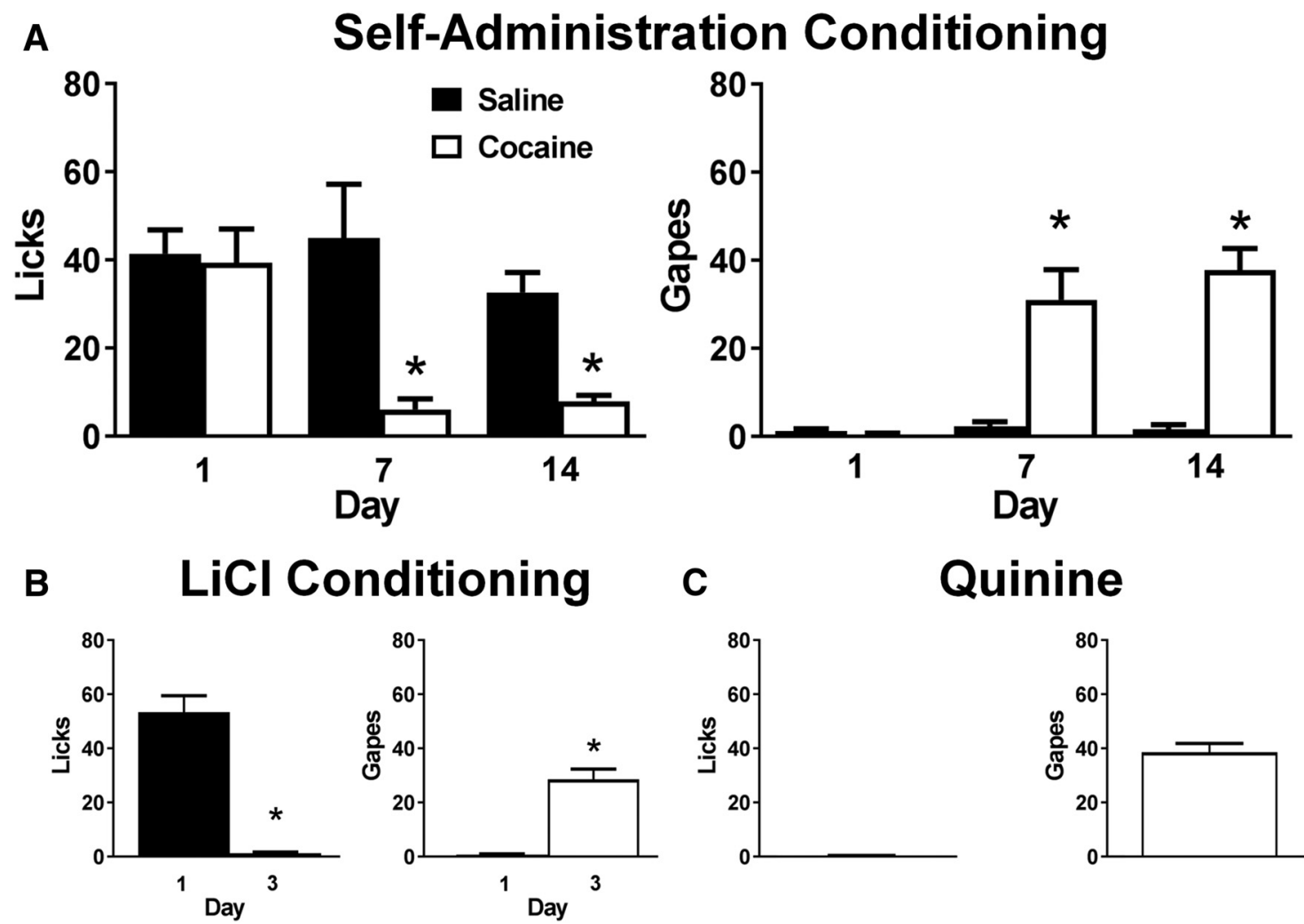

C

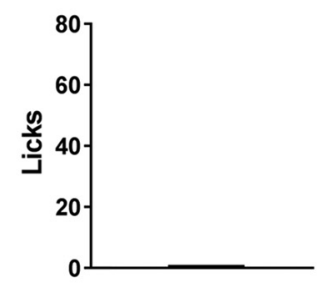

Quinine

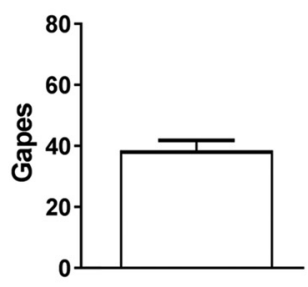

Figure 2. Taste reactivity. $\boldsymbol{A}$, Self-administration conditioning. During saline conditioning, animals had high appetitive taste reactivity (licks, left) and low aversive taste reactivity (gapes, right) across each day of conditioning. Conversely, during cocaine conditioning, animals initially exhibited high appetitive taste reactivity, but this significantly decreased after repeated days of conditioning (left). Simultaneously, repeated days of cocaine conditioning significantly increased aversive taste reactivity (right). ${ }^{*} p<0.05$, days 7 and 14 compared with day $1 . B$, LiCl conditioning. $\mathrm{LiCl}$ conditioning significantly decreased appetitive taste reactivity (left) and increased aversive taste reactivity (right). ${ }^{*} p<0.05$, day 3 compared with day 1. C, Quinine. Quinine elicited low levels of appetitive taste reactivity (left) and high aversive taste reactivity (right). All error bars represent SEM.

efficient of determination $\left(r^{2}\right)$ as a measure of the proportion of the variance in the dependent variable that is predictable from the independent variables. Putative interneurons, defined as cells that had a peaktrough latency $\leq 200 \mu$ s (Mitchell et al., 2007), were excluded from the analysis; these accounted for $4.4 \%$ of all neurons.

\section{Histology}

At the end of all experiments, rats were deeply anesthetized with ketamine/xylazine. A $13.5 \mu \mathrm{A}$ current was passed through each recording wire for $5 \mathrm{~s}$, after which the rat was decapitated and the brain was removed. Brains were postfixed in a solution of $20 \%$ sucrose and $3 \%$ potassium ferricyanide in $10 \%$ buffered formalin and frozen, and $40 \mu \mathrm{m}$ sections were taken through the forebrain. Sections were mounted on slides, and electrode tip locations were visualized using a bright-field microscope. Placements were verified using a stereotaxic atlas (Paxinos and Watson, 1998).

\section{Results}

Aversive taste reactivity is elicited by cocaine-paired saccharin, LiCl-paired saccharin, and quinine

Saline-conditioned animals maintained a predominantly appetitive profile in response to infusion of the intraoral saccharin throughout days 1,7 , and 14 of conditioning (change across conditioning day: licks: $F_{(2,20)}=1.18, p=0.327$; gapes: $F_{(2,20)}=0.52$, $p=0.604$; Fig. $2 A$, left). However, animals conditioned with cocaine switched from a predominantly appetitive profile to a predominantly aversive profile (change across conditioning day: licks: $F_{(1.17,14.00)}=16.76, p=0.001$; gapes: $F_{(1.50,17.97)}=20.26$, $p<0.001$; Fig. $2 A$, right). This finding shows that a palatable saccharin solution is devalued as it comes to predict impending but delayed cocaine, consistent with our prior studies (Wheeler et al., 2008; Green et al., 2015; Hurley et al., 2017). Similarly, animals conditioned with $\mathrm{LiCl}$ showed a switch during intraoral infusions from a predominantly appetitive profile on day 1 (before $\mathrm{LiCl}$ injection) to a predominantly aversive profile on day 3 (after two sessions with $\mathrm{LiCl}$ injection after tastant infusion) of conditioning ( $\mathrm{LiCl}$ : licks: $t_{(13)}=8.58, p<0.001$; gapes: $t_{(13)}=$ 7.38, $p<0.001$; Fig. $2 B$ ). Finally, all rats showed aversive reactions to quinine (Fig. 2C). Animals made $22.14 \pm 1.03$ responses per session for cocaine (consuming $20.66 \pm 0.99 \mathrm{mg} / \mathrm{kg} / \mathrm{session}$ ) and $7.32 \pm 0.85$ responses per session for saline.

Rats exhibit different patterns of aversive taste reactivity after cocaine-paired saccharin compared with LiCl-paired saccharin or quinine

Although infusion of all three aversive tastants resulted in similar numbers of total gapes $\left(F_{(3,57)}=1.56, p=0.208\right.$; Fig. $\left.3 A\right)$, cocaine-paired saccharin yielded different behavioral patterns than did LiCl-paired saccharin or quinine. First, the time course of gaping behavior differed between groups, as gapes significantly decreased as a function of time in the quinine and $\mathrm{LiCl}$ groups but not in the cocaine groups (Group $\times$ Time Bin: $F_{(9.61,182.55)}=$ $7.75, p<0.001)$. Specifically, Bonferroni's post hoc tests comparing bin 1 with bins 3 and 5 were significant for the $\mathrm{LiCl}$ and quinine groups, but not the cocaine groups (Fig. $3 B$; each bin comprised nine trials). Second, rats infused with quinine or $\mathrm{LiCl}$ paired saccharin often ejected or dripped liquid out of their mouths (drips), whereas this was only rarely seen after infusion of cocaine-paired saccharin $\left(F_{(3,57)}=10.90, p<0.001\right.$; Fig. $\left.3 C\right)$. Furthermore, drips increased in tandem with the decrease in 

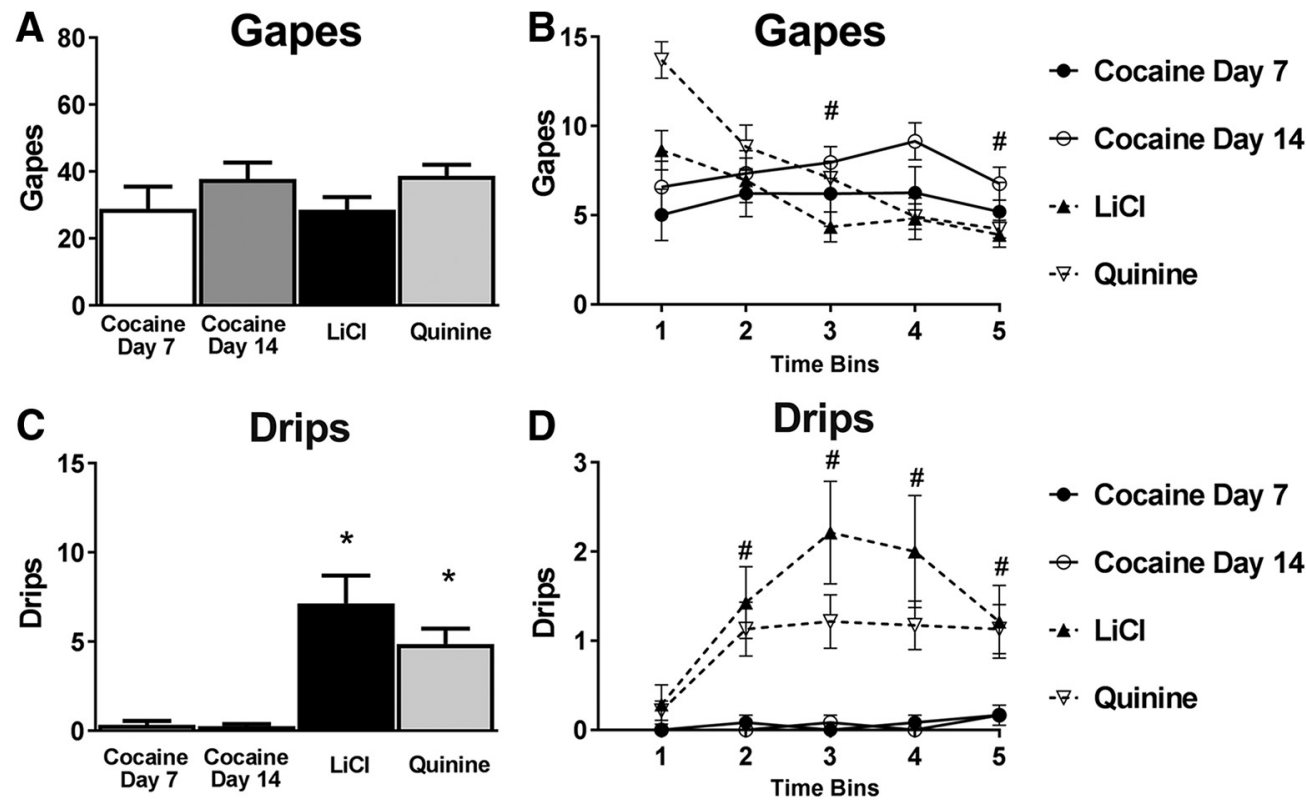

Figure 3. Comparison of aversive taste reactivity between groups. $\boldsymbol{A}$, Cocaine-paired saccharin, LiCl-paired saccharin, and quinine elicited similar overall numbers of gapes. $\boldsymbol{B}$, LiCl- and quinine-induced gapes significantly decreased throughout the session, but cocaine-induced gapes did not. ${ }^{*} p<0.05$, both $\mathrm{LiCl}$ and quinine time bins individually compared with bin 1 , but not cocaine. C, LiCl-paired saccharin and quinine elicited significantly more drips than did cocaine. ${ }^{*} p<0.05$. D, Drips significantly increased throughout the session. ${ }^{\#} p<0.05$, all groups combined at each time bin compared with time bin 1. All error bars represent SEM.

gapes, suggesting that this behavior may have partially replaced gapes as the session progressed $\left(F_{(4,228)}=5.30, p<0.001\right)$. Bonferroni's post hoc tests comparing bin 1 with all other bins were significant when collapsing across the cocaine, $\mathrm{LiCl}$, and quinine groups (Fig. 3D). The increase in drips was specific to the $\mathrm{LiCl}$ and quinine groups (and did not occur in the cocaine groups; Group $\times$ Time Bin: $\left.F_{(12,228)}=1.96, p=0.028\right)$. When examining other measures of aversive taste reactivity, forelimb flails decreased across time bins in the quinine group but not the other groups $\left(\right.$ Group $\times$ Time Bin: $\left.F_{(10.28,178.09)}=1.91, p=0.045\right)$, and there were significantly fewer chin-to-floor rubs in the cocaine groups compared with the other groups $\left(F_{(3,52)}=3.48, p=\right.$ 0.022 ). These findings highlight fundamental differences in aversive taste reactivity in the cocaine versus the $\mathrm{LiCl}$ or quinine conditions.

\section{A distinct population of RAIC neurons encodes the shift in taste reactivity induced by cocaine-paired saccharin}

Of 306 RAIC neurons recorded on day 1, two types of neural firing patterns were observed relative to intraoral tastant infusions. The first type, termed "early-firing" neurons, exhibited phasic changes (increases or decreases) in the firing rate within $2 \mathrm{~s}$ of intraoral infusions (Fig. 4A). During day 1 of conditioning across all groups, 93 of 306 RAIC neurons were classified as earlyfiring neurons. A majority of these responses were excitatory ( $n=63$ cells, $68 \%$ ), whereas the rest were inhibitory ( $n=30$ cells, $32 \%$; Fig. $4 B$ ). However, the distribution of early-firing phasic responses differed as a function of training days across conditioning groups. In the cocaine group, the majority of neurons showed an excitatory response to saccharin infusions on day 1 . However, repeated taste-drug pairings shifted this neural profile from predominantly excitatory to mostly inhibitory on days 7 and 14 of training $\left(\chi^{2}=10.42, p=0.005\right.$; Fig. $4 C$, left). Notably, this significant shift from mostly excitatory firing on day 1 to predominately inhibitory activity on later conditioning days was not seen after saline pairings, $\mathrm{LiCl}$ pairings or during administration of quinine (saline: $\chi^{2}=3.02, p=0.221$; LiCl: $\chi^{2}=0.57, p=$ 0.449 ; quinine: $\chi^{2}=0.19, p=0.666$; Fig. $4 C$ ). These findings did not differ between the rostral or caudal RAIC (all $p$ values $>0.05$ ).

A second population of RAIC neurons was identified that was also modulated by intraoral infusions, but with a longer latency of onset (beginning within 3-4 s of infusion onset). Examples of these neurons, termed "late-firing" cells, are shown in Figure $5 \mathrm{~A}$. During day 1 of conditioning across all groups, 92 of 306 RAIC neurons exhibited either increases or decreases in cell firing in the 3 or $4 \mathrm{~s}$ bins after intraoral infusions (Fig. $5 B$ ). In contrast to early-firing neurons, a majority of these responses were inhibitory $(n=54,59 \%)$ whereas the rest were excitatory $(n=38,41 \%$; $\chi^{2}$ test comparing excitatory/inhibitory ratios of early-firing and late-firing neurons on day 1 of conditioning: $\chi^{2}=13.04, p<$ $0.001)$. Importantly, late-firing neurons did not track the shift in taste reactivity for the cocaine group $\left(\chi^{2}=1.92, p=0.383\right)$ nor in the other groups (saline: $\chi^{2}=1.15, p=0.562$; LiCl: $\chi^{2}=1.63$, $p=0.202$; quinine: $\chi^{2}=2.36, p=0.124$; Fig. $5 C$ ).

Early (but not late) inhibitory RAIC activity during infusion of cocaine-paired saccharin predicts subsequent early-session drug taking

The above findings show that early-firing RAIC neurons uniquely track the emergence of negative affect to drug-paired saccharin, as reflected in a shift from mostly excitatory firing on day 1 of training to predominately inhibitory activity with repeated taste-drug pairings for both days 7 and 14 of training. Here, we investigated the relationship between this shift in RAIC activity during intraoral infusions and individual differences in specific aspects of drug-seeking behavior during subsequent selfadministration. First, the percent of early-firing neurons that had an inhibitory response to saccharin infusion on test days was calculated for each rat. This value was then correlated with cocaine loading and the latency to first press during self-administration for each 

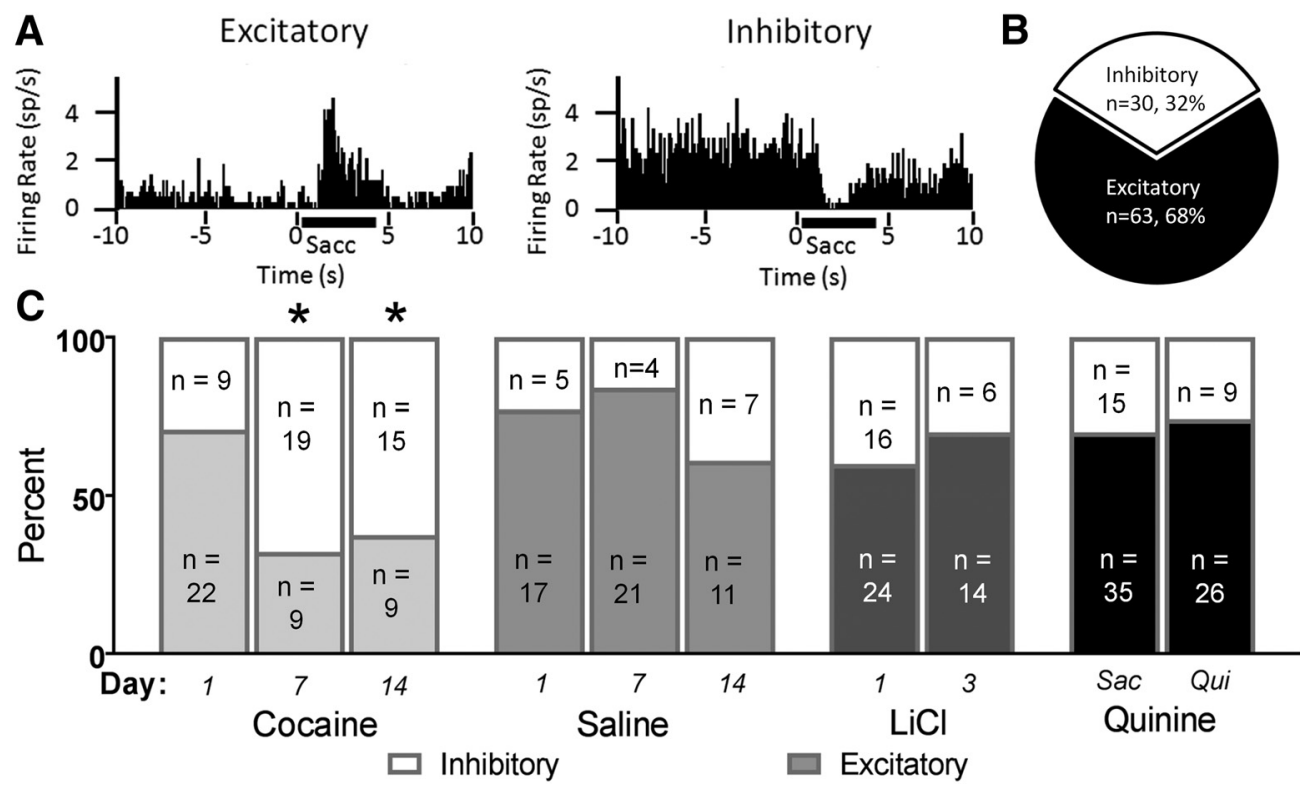

Figure 4. Early-firing RAIC neurons track cocaine-induced devaluation of natural reward. $A$, Perievent histograms for representative early-firing RAIC neurons showing either excitations (left) or inhibitions (right) within $2 \mathrm{~s}$ of tastant infusion. $\boldsymbol{B}$, The population of neurons exhibits a predominantly excitatory profile in response to saccharin on the first day of conditioning for all groups. C, Neurons in the cocaine-paired group showed a significant shift from predominantly excitatory to predominantly inhibitory. No such change was observed in the other groups. ${ }^{*} p<0.05$.
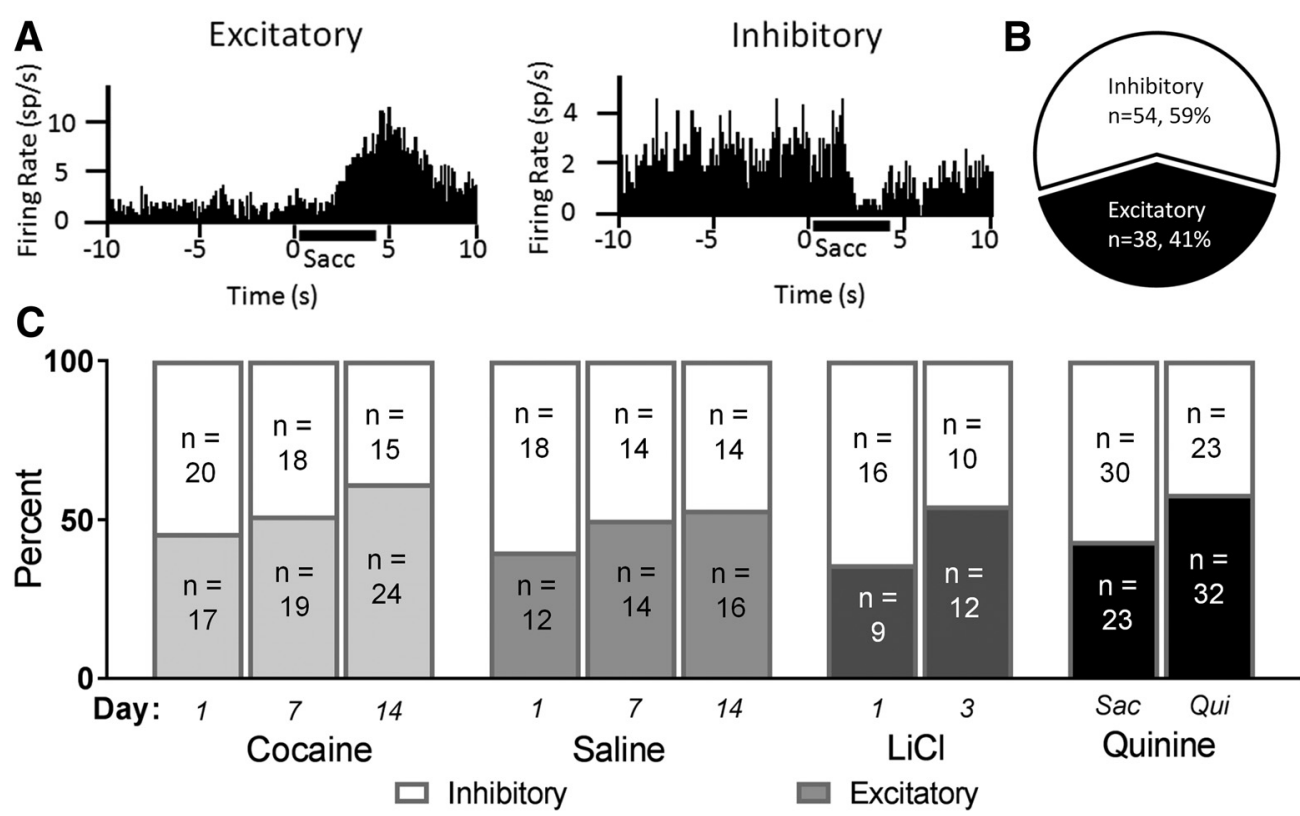

Figure 5. Late-firing RAIC neurons do not track hedonic shifts. A, Perievent histograms for representative late-firing RAIC neurons showing either excitations (left) or inhibitions (right) in the 3 or $4 \mathrm{~s}$ time bin of tastant infusion. $\boldsymbol{B}$, The population of neurons exhibits a predominantly inhibitory profile in response to saccharin on the first day of conditioning for all groups. $\boldsymbol{C}$, Population dynamics did not shift in any of the experimental groups.

animal (indicators of motivation for drug), as well as the number of gapes on those days (an indicator of the dysphoric state of each rat). We found that the percent of early-firing inhibitory neurons predicted aspects of heightened drug seeking, with high-percent inhibitory activity predicting loading $\left[r^{2}=0.68, p<0.001\right.$; Fig. $6 A$; individually significant on day $7\left(r^{2}=0.84, p=0.004\right)$ and day 14 $\left.\left(r^{2}=0.59, p=0.026\right)\right]$ and latency to first press $\left(r^{2}=0.28, p=\right.$ 0.043 ; Fig. $6 B)$ but not gaping behavior $\left(r^{2}=0.02, p=0.655\right.$; Fig. $6 C)$. We also conducted similar correlations for late-firing inhibitory neurons for each rat. However, no significant rela- tionships were observed between percent of inhibitory latefiring neurons and loading behavior $\left(r^{2}=0.03, p=0.493\right.$; Fig. $7 A)$, latency to first press $\left(r^{2}=0.08, p=0.223\right.$; Fig. $\left.7 B\right)$, or gapes $\left(r^{2}=0.02, p=0.520\right.$; Fig. $\left.7 C\right)$. Collectively, these data suggest that a distinct population of early-firing (but not latefiring) neurons in the RAIC that track cocaine-induced devaluation of reward predicts low motivation to consume the drug (i.e., less loading responses and slower latencies) but is not linked to aversive responses elicited by the cocaine-paired sweet. 
A

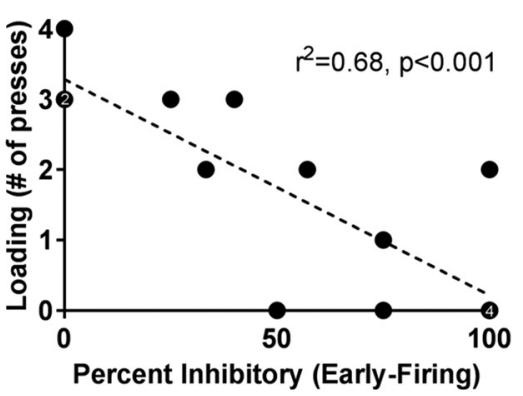

B Latency to First Press
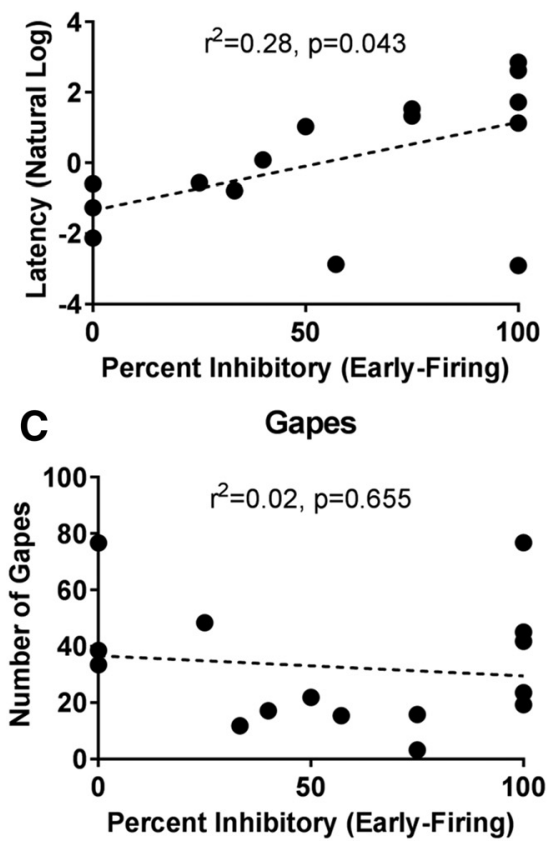

Figure 6. Population dynamics in early-firing RAIC neurons predict indices of motivation for cocaine, but not aversion per se. Percent inhibitory early-firing neurons are significantly correlated with loading $(\boldsymbol{A})$ and latency to first press $(\boldsymbol{B})$ but not aversive gapes ( $\boldsymbol{C}$. Numbers indicate multiple overlapping data points.

\section{Histology}

Data were only included for cells recorded within the RAIC. The location of these cells across recording sessions is depicted in Figure 8.

\section{Discussion}

A taste cue that predicts impending but delayed cocaine availability elicits a negative affective state associated with heightened drug seeking (Wheeler et al., 2008, 2011; Carelli and West, 2014; Colechio et al., 2014; Green et al., 2015). Here, we show that a discrete neural subpopulation in the RAIC (early-firing neurons) encodes this cocaine-induced (but not LiCl-related) negative affective state and concurrent devaluation of natural reward. Importantly, although aversive responses (gapes) were observed for all three tastants (saccharin paired with cocaine or $\mathrm{LiCl}$ infusions or quinine infusions), aversive profiles and the time course of expression were not identical for each. Finally, we observed significant correlations between early-firing inhibitory RAIC firing during repeated taste-drug pairings and indices of motivated behavior for drug (loading and latency to respond), but not to aversive gaping behavior. Collectively, these findings indicate

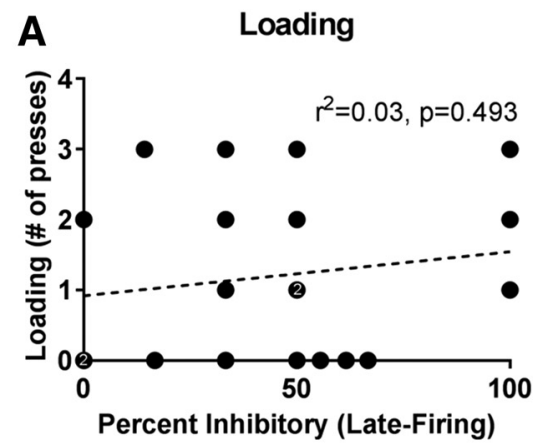

B Latency to First Press
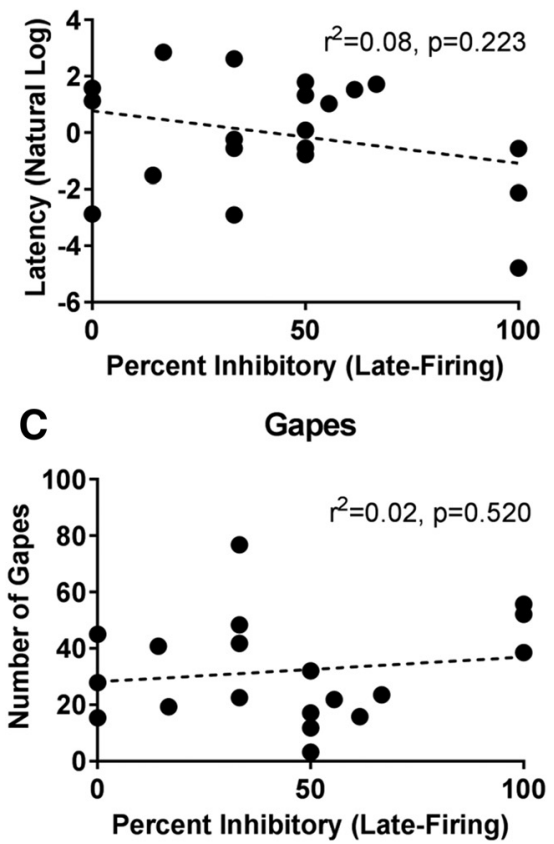

Figure 7. Population dynamics in late-firing RAIC neurons did not predict behavior. Percent inhibitory late-firing neurons do not predict loading $(\boldsymbol{A})$, latency $(\boldsymbol{B})$, or gapes $(\boldsymbol{C})$. Numbers indicate multiple overlapping data points.

that cocaine-paired tastants elicit unique aspects of aversive behaviors and that the RAIC plays a role in modulating drugseeking behaviors driven by drug-induced dysphoria but not negative affect per se. The implications of these findings are discussed below.

Support for fundamental differences between drug-induced versus traditional conditioned taste aversion

The relationship between aversion to the drug-paired taste and subsequent drug seeking indicates that the negative affect elicited by the tastant paired with cocaine is fundamentally different from that elicited by more traditional agents of conditioned taste aversion, such as LiCl. Indeed, it has been proposed that rats avoid intake of a saccharin solution paired with a drug of abuse because they are anticipating the rewarding, rather than the aversive, properties of the drug (Grigson, 1997, 2008; Grigson and Twining, 2002). In the present task, rats given intraoral saccharin solution paired with impending but delayed cocaine show indices of aversion (gaping) to the sweet and enhanced drug seeking, in support of the reward comparison model (Grigson, 1997, 2008; Grigson and Twining, 2002; Wheeler et al., 2008; Colechio et al., 2014). Here, we offer further evidence for this distinction by 


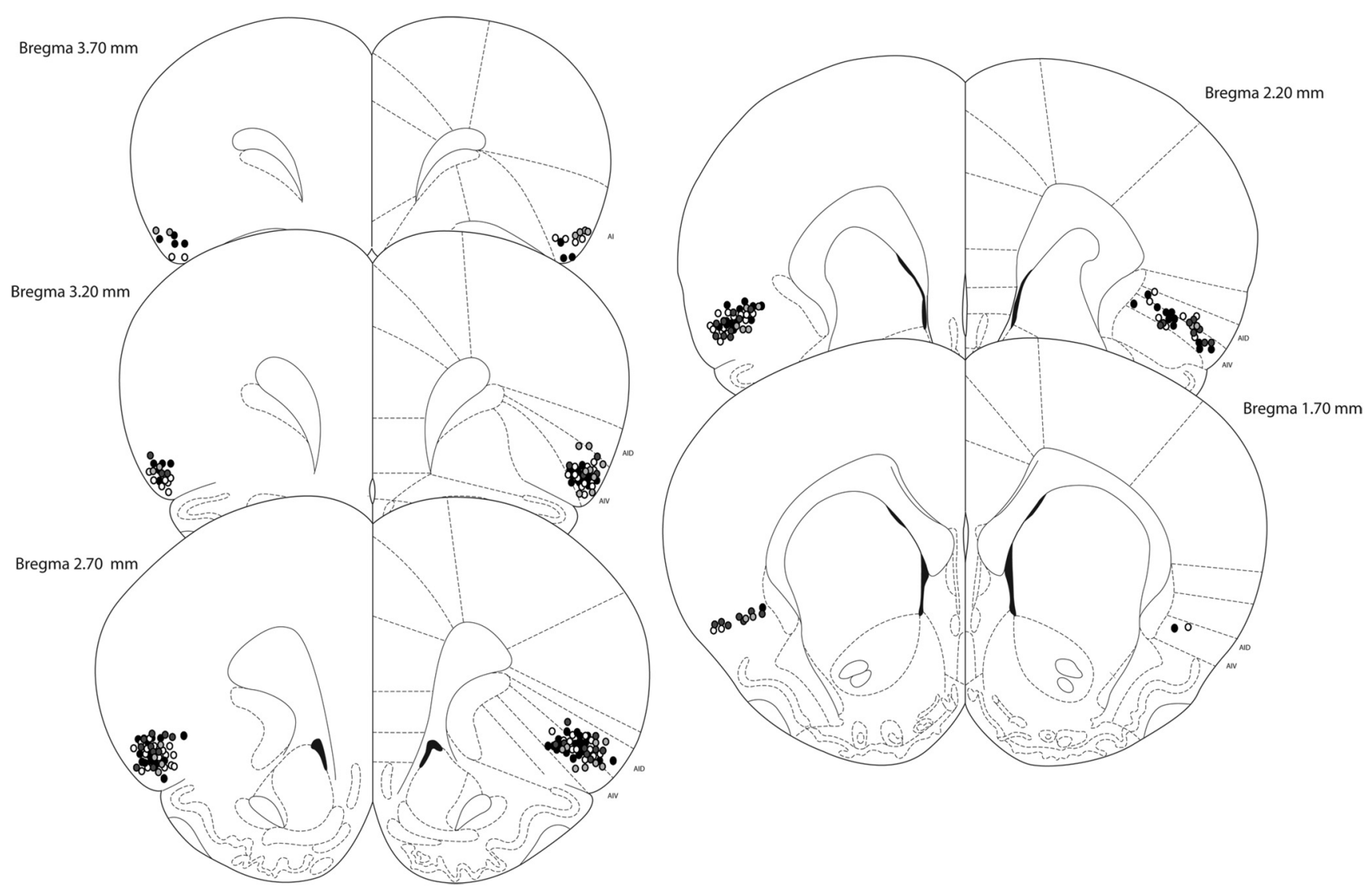

Figure 8. Location of recorded neurons in the RAIC. White circles, Saline; light gray circles, LiCl; dark gray circles, quinine; black circles, cocaine. AID = dorsal agranular insular cortex, AIV = ventral agranular insular cortex.

demonstrating that aversive taste reactivity after cocaine-paired saccharin is qualitatively different from that after LiCl-paired saccharin or intraoral infusion of the bitter, aversive tastant quinine.

Specifically, cocaine-paired saccharin, LiCl-paired saccharin, and quinine each elicited high aversive taste reactivity, replicating previous work (Grill and Norgren, 1978; Grigson and Twining, 2002; Roitman et al., 2005, 2010; Wheeler et al., 2008; Colechio et al., 2014). However, we also examined the time course of taste reactivity within each session and found a significant shift across trials from gapes to passive drips in $\mathrm{LiCl}$ and quinine rats but not cocaine rats. These divergent patterns of taste reactivity may suggest that the different groups experienced distinct affective states. We and others have suggested that the gapes seen in the cocaine paradigm may in part reflect craving for the delayed, but impending cocaine (Wheeler et al., 2008; Colechio et al., 2014). Indeed, the number of gapes elicited predicts early loading behavior during self-administration (Wheeler et al., 2008; Green et al., 2015), and no such gapes were seen when saccharin was paired with immediate cocaine injection (Parker, 1995). Thus, the continuity of gapes across trials in the cocaine-paired rats may reflect the persistence of drug craving that is not reduced until access to self-administration is granted. In contrast, it is presumed that no such craving is experienced with the other two aversive tastants (the sweet paired with $\mathrm{LiCl}$ or the innately aversive bitter quinine), indicating that the shift from gapes to passive drips for those agents may instead reflect a passive aversive response to intraoral infusion of unavoidable aversive tastants.
Early-firing RAIC neurons shift activity in opposition to motivated drug-seeking behaviors but do not specifically relate to aversive state

Early in training, a population of early-firing neurons in the RAIC was predominantly excited by intraoral saccharin infusions but became predominantly inhibited by the sweet after repeated pairings with cocaine. Interestingly, the degree of inhibition of RAIC neurons correlated with subsequent early loading behavior and latency to respond for cocaine, once the drug was again available. However, animals that exhibited a strong inhibitory profile with repeated taste-drug pairings showed low levels of drug loading and slower latencies to respond for cocaine, once available. These findings suggest that the strong inhibitory profile seen in the RAIC developed in opposition to drug-taking behavior. Notably, this inhibitory neural profile occurred during tastant infusion, well before the animals had access to drug in our task, during a period hypothesized to be a high-craving state when the animal must wait for access to cocaine (Wheeler et al., 2008; Colechio et al., 2014). Thus, our findings suggest that over the course of taste-drug pairings, early-firing inhibitory RAIC neurons may act to suppress cocaine craving in our task, since those animals with higher-percent inhibitory neurons had reduced motivation to pursue cocaine once it became available. Interestingly, this interpretation has support from the clinical literature, where human subjects asked to suppress their craving for drugs or food exhibit decreased BOLD activity in the insula (Wang et al., 2009; Volkow et al., 2010), and lesion of the insula in human subjects decreases drug craving and increases the likelihood that 
individuals will quit (Naqvi et al., 2007; Suñer-Soler et al., 2012). Furthermore, preclinical work has shown that inactivation of the RAIC decreases drug-seeking behavior (Seif et al., 2013; Cosme et al., 2015; Arguello et al., 2017; Venniro et al., 2017). Together, these studies highlight an important role for the insula in drug craving.

Notably, percent inhibitory activity of early-firing RAIC neurons after repeated taste-drug pairings did not correlate with aversive taste reactivity (gapes). Furthermore, whereas earlyfiring RAIC cells did track cocaine-induced devaluation, they did not track the hedonic shifts accompanying LiCl-paired saccharin. Of note, the emergence of this negative affective state in our task is tracked by a subset of NAc neurons (Wheeler et al., 2008; Haake et al., 2018), as well as shifts in rapid dopamine signaling in the NAc (Wheeler et al., 2011; Hurley et al., 2017). Collectively, these findings suggest that the RAIC does not track negative affect per se and sets this structure apart from the NAc, which does track these shifts (Roitman et al., 2005, 2010) and whose activity correlates with gaping (Wheeler et al., 2008). These differences may hint at distinct roles for the two regions. The NAc is often considered to be a limbic-motor interface (Mogenson et al., 1980; Groenewegen et al., 1996) and may act as a general integrator of hedonic/aversive value (Carlezon and Thomas, 2009). In contrast, the RAIC may function to transmit information about tastant-induced craving to the NAc, which may then be integrated with other inputs in the NAc to compute affect value.

There are some limitations to this study. First, there were no control groups that included operant conditioning for a reward other than cocaine (such as food). It would be interesting to determine whether neural activity in the RAIC tracks saccharin paired with food (versus cocaine) in a similar manner as saccharin-cocaine pairings. However, such a study would need to be undertaken with caution, as the relationship between tastantfood pairings has proven exceptionally complex (Lucas et al., 1990). Second, the shift in RAIC activity may have tracked the change in behavior rather than a shift in craving or hedonic value. However, since RAIC correlated with our measures of craving/ hedonic value (i.e., loading and latency) but not gapes and licks, we believe RAIC activity is related, to some degree, to the former. Finally, it is possible that the behavioral differences we see between the cocaine group and the $\mathrm{LiCl}$ and quinine groups are attributable to the longer training experienced by the cocaine group. Although possible, we have preliminary unpublished findings ( $n=3$ rats) indicating that the time course of aversive orofacial responses for the saccharin-cocaine group was similar between early (days 2 and 3) and late (days 7 and 14) training sessions. These data indicate that the differences in temporal gaping dynamics are not the result of different duration of training for the cocaine group.

\section{Concluding remarks}

The present study demonstrated that cocaine-paired saccharin elicits markedly different taste reactivity than LiCl-paired saccharin or quinine. These differences in taste reactivity were reflected in the RAIC, where a discrete set of neurons (early firing) tracked the shift in value after cocaine conditioning but not that induced by LiCl-paired saccharin or quinine. Furthermore, animals that inhibited activity in these neurons during saccharin infusion exhibited low cocaine-taking behavior, suggesting a mechanism in the RAIC that develops in opposition to cue-induced craving. These findings support studies implicating the RAIC in addictive processes (Contreras et al., 2012; Seif et al., 2013; Cosme et al., 2015; Arguello et al., 2017; Venniro et al., 2017). Future work is needed to investigate the role that the RAIC and its connections with regions such as the NAc, amygdala, and thalamus play in drug-associated craving and negative affect.

\section{References}

Arguello AA, Wang R, Lyons CM, Higginbotham JA, Hodges MA, Fuchs RA (2017) Role of the agranular insular cortex in contextual control over cocaine-seeking behavior in rats. Psychopharmacology 234:2431-2441. CrossRef Medline

Berridge KC (2000) Measuring hedonic impact in animals and infants: microstructure of affective taste reactivity patterns. Neurosci Biobehav Rev 24:173-198. CrossRef Medline

Brandon TH (1994) Negative affect as motivation to smoke. Curr Dir Psychol Sci 3:33-37. CrossRef

Carelli RM, Deadwyler SA (1996) Dose-dependent transitions in nucleus accumbens cell firing and behavioral responding during cocaine selfadministration sessions in rats. J Pharmacol Exp Ther 277:385-393. Medline

Carelli RM, West EA (2014) When a good taste turns bad: neural mechanisms underlying the emergence of negative affect and associated natural reward devaluation by cocaine. Neuropharmacology 76:360-369. CrossRef Medline

Carelli RM, Ijames SG, Crumling AJ (2000) Evidence that separate neural circuits in the nucleus accumbens encode cocaine versus "natural" (water and food) reward. J Neurosci 20:4255-4266. CrossRef Medline

Carlezon WA Jr, Thomas MJ (2009) Biological substrates of reward and aversion: a nucleus accumbens activity hypothesis. Neuropharmacology 56: 122-132. CrossRef Medline

Colechio EM, Imperio CG, Grigson PS (2014) Once is too much: conditioned aversion develops immediately and predicts future cocaine selfadministration behavior in rats. Behav Neurosci 128:207-216. CrossRef Medline

Contreras M, Billeke P, Vicencio S, Madrid C, Perdomo G, González M, Torrealba F (2012) A role for the insular cortex in long-term memory for context-evoked drug craving in rats. Neuropsychopharmacology 37: 2101-2108. CrossRef Medline

Cosme CV, Gutman AL, LaLumiere RT (2015) The dorsal agranular insular cortex regulates the cued reinstatement of cocaine-seeking, but not foodseeking, behavior in rats. Neuropsychopharmacology 40:2425-2433 CrossRef Medline

Gaznick N, Tranel D, McNutt A, Bechara A (2014) Basal ganglia plus insula damage yields stronger disruption of smoking addiction than basal ganglia damage alone. Nicotine Tob Res 16:445-453. CrossRef Medline

Geddes RI, Han L, Baldwin AE, Norgren R, Grigson PS (2008) Gustatory insular cortex lesions disrupt drug-induced, but not lithium chlorideinduced, suppression of conditioned stimulus intake. Behav Neurosci 122:1038-1050. CrossRef Medline

Gloria R, Angelos L, Schaefer HS, Davis JM, Majeskie M, Richmond BS, Curtin JJ, Davidson RJ, Baker TB (2009) An fMRI investigation of the impact of withdrawal on regional brain activity during nicotine anticipation. Psychophysiology 46:681-693. CrossRef Medline

Green JL, Dykstra LA, Carelli RM (2015) Examination of cocaine dose in a preclinical model of natural reward devaluation by cocaine. Behav Pharmacol 26:398-402. CrossRef Medline

Grigson PS (1997) Conditioned taste aversions and drugs of abuse: a reinterpretation. Behav Neurosci 111:129-136. CrossRef Medline

Grigson PS (2008) Reward comparison: the Achilles' heel and hope for addiction. Drug Discov Today Dis Models 5:227-233. Medline

Grigson PS, Twining RC (2002) Cocaine-induced suppression of saccharin intake: a model of drug-induced devaluation of natural rewards. Behav Neurosci 116:321-333. CrossRef Medline

Grill HJ, Norgren R (1978) The taste reactivity test. I. Mimetic responses to gustatory stimuli in neurologically normal rats. Brain Res 143:263-279. CrossRef Medline

Groenewegen HJ, Wright CI, Beijer AV (1996) The nucleus accumbens: gateway for limbic structures to reach the motor system? Prog Brain Res 107:485-511. CrossRef Medline

Haake RM, West EA, Wang X, Carelli RM (2018) Drug-induced dysphoria is enhanced following prolonged cocaine abstinence and dynamically tracked by nucleus accumbens neurons. Addict Biol. Advance online publication. Retrieved from May 2, 2018. doi: 10.1111/adb.12627.

Hollander JA, Carelli RM (2005) Abstinence from cocaine self-administration 
heightens neural encoding of goal-directed behaviors in the accumbens. Neuropsychopharmacology 30:1464-1474. CrossRef Medline

Hurley SW, West EA, Carelli RM (2017) Opposing roles of rapid dopamine signaling across the rostral-caudal axis of the nucleus accumbens shell in drug-induced negative affect. Biol Psychiatry 82:839-846. CrossRef Medline

Jasmin L, Burkey AR,Granato A, Ohara PT (2004) Rostral agranular insular cortex and pain areas of the central nervous system: a tract-tracing study in the rat. J Comp Neurol 468:425-440. CrossRef Medline

Kilts CD, Schweitzer JB, Quinn CK, Gross RE, Faber TL, Muhammad F, Ely TD, Hoffman JM, Drexler KP (2001) Neural activity related to drug craving in cocaine addiction. Arch Gen Psychiatry 58:334-341. CrossRef Medline

Koob GF, Volkow ND (2010) Neurocircuitry of addiction. Neuropsychopharmacology 35:217-238. CrossRef Medline

Lucas GA, Timberlake W, Gawley DJ, Drew J (1990) Anticipation of future food: suppression and facilitation of saccharin intake depending on the delay and type of future food. J Exp Psychol Anim B 16:169-177. CrossRef

Mitchell JF, Sundberg KA, Reynolds JH (2007) Differential attentiondependent response modulation across cell classes in macaque visual area V4. Neuron 55:131-141. CrossRef Medline

Mogenson GJ, Jones DL, Yim CY (1980) From motivation to actions: functional interface between the limbic system and the motor system. Prog Neurobiol 14:69-97. CrossRef Medline

Naqvi NH, Rudrauf D, Damasio H, Bechara A (2007) Damage to the insula disrupts addiction to cigarette smoking. Science 315:531-534. CrossRef Medline

Parker LA (1995) Rewarding drugs produce taste avoidance, but not taste aversion. Neurosci Biobehav Rev 19:143-151. CrossRef

Paxinos G, Watson C (1998) The rat brain in stereotaxic coordinates, Ed 3. San Diego: Academic.

Roitman MF, Wheeler RA, Carelli RM (2005) Nucleus accumbens neurons are innately tuned for rewarding and aversive taste stimuli, encode their predictors, and are linked to motor output. Neuron 45:587-597. CrossRef Medline

Roitman MF, Wheeler RA, Tiesinga PH, Roitman JD, Carelli RM (2010) Hedonic and nucleus accumbens neural responses to a natural reward are regulated by aversive conditioning. Learn Mem 17:539-546. CrossRef

Seif T, Chang SJ, Simms JA, Gibb SL, Dadgar J, Chen BT, Harvey BK, Ron D, Messing RO, Bonci A, Hopf FW (2013) Cortical activation of accumbens hyperpolarization-active NMDARs mediates aversion-resistant alcohol intake. Nat Neurosci 16:1094-1100. CrossRef Medline
Sinha R, Garcia M, Paliwal P, Kreek MJ, Rounsaville BJ (2006) Stressinduced cocaine craving and hypothalamic-pituitary-adrenal responses are predictive of cocaine relapse outcomes. Arch Gen Psychiatry 63:324331. CrossRef Medline

Solomon RL, Corbit JD (1974) An opponent-process theory of motivation: I. Temporal dynamics of affect. Psychol Rev 81:119-145. CrossRef Medline

Suñer-Soler R, Grau A, Gras ME, Font-Mayolas S, Silva Y, Dávalos A, Cruz V, Rodrigo J, Serena J (2012) Smoking cessation 1 year poststroke and damage to the insular cortex. Stroke 43:131-136. CrossRef Medline

Venniro M, Caprioli D, Zhang M, Whitaker LR, Zhang S, Warren BL, Cifani C, Marchant NJ, Yizhar O, Bossert JM, Chiamulera C, Morales M, Shaham Y (2017) The anterior insular cortex $\rightarrow$ central amygdala glutamatergic pathway is critical to relapse after contingency management. Neuron 96:414-427.e8. CrossRef Medline

Volkow ND, Fowler JS, Wang GJ, Telang F, Logan J, Jayne M, Ma Y, Pradhan K, Wong C, Swanson JM (2010) Cognitive control of drug craving inhibits brain reward regions in cocaine abusers. Neuroimage 49:25362543. CrossRef Medline

Wang GJ, Volkow ND, Fowler JS, Cervany P, Hitzemann RJ, Pappas NR, Wong CT, Felder C (1999) Regional brain metabolic activation during craving elicited by recall of previous drug experiences. Life Sci 64:775784. CrossRef Medline

Wang GJ, Volkow ND, Telang F, Jayne M, Ma Y, Pradhan K, Zhu W, Wong CT, Thanos PK, Geliebter A, Biegon A, Fowler JS (2009) Evidence of gender differences in the ability to inhibit brain activation elicited by food stimulation. Proc Natl Acad Sci U S A 106:1249-1254. CrossRef Medline

West EA, Carelli RM (2016) Nucleus accumbens core and shell differentially encode reward-associated cues after reinforcer devaluation. J Neurosci 36:1128-1139. CrossRef Medline

Wheeler RA, Carelli RM (2009) Dissecting motivational circuitry to understand substance abuse. Neuropharmacology 56 [Suppl 1]:149-159. CrossRef Medline

Wheeler RA, Twining RC, Jones JL, Slater JM, Grigson PS, Carelli RM (2008) Behavioral and electrophysiological indices of negative affect predict cocaine self-administration. Neuron 57:774-785. CrossRef Medline

Wheeler RA, Aragona BJ, Fuhrmann KA, Jones JL, Day JJ, Cacciapaglia F, Wightman RM, Carelli RM (2011) Cocaine cues drive opposing context-dependent shifts in reward processing and emotional state. Biol Psychiatry 69:1067-1074. CrossRef Medline

Wise RA, Koob GF (2014) The development and maintenance of drug addiction. Neuropsychopharmacology 39:254-262. CrossRef Medline 